University of Nebraska - Lincoln

DigitalCommons@University of Nebraska - Lincoln

Sociology Department, Faculty Publications

Sociology, Department of

2007

\title{
Sexual Health of Homeless Youth: Prevalence and Correlates of Sexually Transmissible Infections
}

\author{
Kimberly A. Tyler \\ University of Nebraska-Lincoln, kim@ktresearch.net \\ Les B. Whitbeck \\ University of Nebraska-Lincoln, Iwhitbeck2@unl.edu \\ Xiaojin Chen \\ Tulane University, xchen1@tulane.edu \\ Kurt Johnson \\ Pennsylvania State University, 327A Pond, University Park, PA
}

Follow this and additional works at: https://digitalcommons.unl.edu/sociologyfacpub

Part of the Sociology Commons

Tyler, Kimberly A.; Whitbeck, Les B.; Chen, Xiaojin; and Johnson, Kurt, "Sexual Health of Homeless Youth: Prevalence and Correlates of Sexually Transmissible Infections" (2007). Sociology Department, Faculty Publications. 49.

https://digitalcommons.unl.edu/sociologyfacpub/49

This Article is brought to you for free and open access by the Sociology, Department of at DigitalCommons@University of Nebraska - Lincoln. It has been accepted for inclusion in Sociology Department, Faculty Publications by an authorized administrator of DigitalCommons@University of Nebraska - Lincoln. 


\title{
Sexual Health of Homeless Youth: Prevalence and Correlates of Sexually Transmissible Infections
}

\author{
Kimberly A. Tyler,* Les B. Whitbeck, ${ }^{*}$ Xiaojin Chen, ${ }^{* *}$ and Kurt Johnson*** \\ * Department of Sociology, University of Nebraska-Lincoln, 717 Oldfather Hall, Lincoln, NE 68588-0324, USA. \\ ** Department of Sociology, Tulane University, 220 Newcomb Hall, New Orleans, LA 70118, USA. \\ *** Survey Research Center, Pennsylvania State University, 327A Pond, University Park, PA 16802, USA. \\ Corresponding author — K. A. Tyler, email kim@ktresearch.net
}

\begin{abstract}
Background: The study examined risk factors for having ever contracted sexually transmissible infections (STI) among a high-risk sample in midwestern USA.

Methods: A cross sectional survey was conducted among 428 homeless youth aged 16-19 years. Assessed correlates included child maltreatment, street exposure, sexual histories, street experiences and substance use.

Results: Multivariate analyses revealed that males were $86 \%$ less likely to have had STI compared with females (adjusted odds ratio [AOR] $=0.14$; $95 \%$ confidence interval $[\mathrm{CI}]=0.06-0.31)$. Blacks were almost four times more likely $(\mathrm{AOR}=3.71 ; 95 \% \mathrm{CI}=1.80-7.63)$ and other races were over two times more likely ( $\mathrm{AOR}=2.25 ; 95 \% \mathrm{CI}=1.08-4.67$ ) to have had STI compared with whites. For every one unit increase in the number of times youth ran away, there was a $3 \%$ increase in the likelihood of ever having had an STI (AOR $=1.03 ; 95 \% \mathrm{CI}=1.01-1.06)$. For every one unit increase in frequency of condom use there was a $61 \%$ decrease in the likelihood of an STI (AOR $=1.39 ; 95 \%$ CI $=1.10-1.76)$. Finally, youth who traded sex were approximately 2.5 times more likely to have had STI compared with youth who did not trade sex (AOR $=2.36$; $95 \% \mathrm{CI}=1.04-5.34)$. None of the remaining correlates approached multivariate significance.

Conclusions: The amount of time youth spend on the street, their sexual practices, and their subsistence strategies are important correlates of STI and females and non-whites are particularly vulnerable among this high-risk population.
\end{abstract}

\section{Introduction}

Sexually transmitted diseases, or what are now more commonly referred to as sexually transmissible infections (STI), have significant health and economic consequences for both adolescents and society. ${ }^{1}$ Sexually active youth in the USA aged 15 to 24 years acquired 9.1 million new STI in 2000, which represents nearly half of all new infections during that year. ${ }^{2}$ Furthermore, females and some minority groups are likely to experience higher rates of STI compared with males and white youth. ${ }^{1}$

Although youth in general are at greater risk for contracting STI compared with other age groups, homeless youth are likely to be at even higher risk for several different reasons. First, homeless youths' extensive histories of abuse and neglect may result in various health-compromising behaviors including trading sex and substance use. ${ }^{3-5}$ Additionally, the time spent on the street exposes them to drug users, sexual predators and other high-risk individuals who may exploit them and endanger their physical health. ${ }^{6,7}$ Also, homeless youth have extremely low rates of condom usage and numerous sexual partners, ${ }^{6,8-12}$ which increases their risk for contracting STI. Self-reported rates of STI among homeless youth range from $\sim 20 \%$ to $37 \% .{ }^{9,12-14}$ It is estimated that 2.8 million runaway and homeless youth live on the streets of America every day ${ }^{15}$ and because females and some minority groups, who are at greater risk for contracting STI, make up a sizeable portion of the homeless population, ${ }^{16}$ homeless youth are an at-risk population in need of further study.
Researchers studying homeless youth have examined correlates of non-condom use ${ }^{10}$ and HIV or STI testing, ${ }^{14,17}$ and have focused on STI as one of many dependent variables associated with numerous outcomes such as sexual risk or depression. ${ }^{9,18}$ Others have looked at the frequency of risky behaviors including STI but many of these studies are descriptive and have not gone beyond correlates and means tests; ${ }^{12,13,19}$ therefore, very few studies have focused specifically on risk factors associated with contracting STI among homeless youth. Additionally, even though females and some minority groups experience higher rates of STI compared with males and white youth, few studies have examined such relationships. Accordingly, the purpose of the present study is to use multivariate analyses to examine risk factors for STI using a large sample of homeless youth and to examine whether moderating relationships exist. The proposed study is unique because it focuses on a heterogeneous group that experiences numerous risks for contracting STI. Additionally, because acquiring STI can have long-term negative effects on homeless youths' health and well being, it is important to learn more about such risks so that appropriate intervention is possible.

\section{Methods}

Study sample

In total, 428 homeless young people (187 males; 241 females) were interviewed on the streets and in shelters by full time, specially trained survey researchers in midwestern USA. In- 
terviewers were instructed to approach shelter residents and locate eligible respondents in areas of the cities where homeless youth congregate. Study eligibility required young people to be between the ages of 16 and 19 years and homeless. Our definition of "homeless" mandated that the youth currently resided in a shelter, on the street, or lived independently (e.g. friends, transitional living) because they had run away, had been pushed out, or had drifted out of their family of origin. The response rate was $90 \%$.

\section{Data collection}

Interviews were conducted in shelter interview rooms, quiet corners of restaurants and libraries. All interviewers have considerable experience interacting with this group of young people and are very familiar with local street cultures, including knowing where homeless youth congregate. Study procedures were explained and informed consent was obtained from the youth. They were assured that refusal to participate, refusal of any question or stopping the interview process would have no effect on current or future services provided by the outreach agency in which the interviewer was placed. Respondents were paid US \$25 for their participation. The Institutional Review Board at the University of Nebraska-Lincoln approved all procedures.

\section{Measures}

The dependent variable "STI" measured whether youth ever had a sexually transmissible infection such as crabs, gonorrhea, or syphilis (i.e. yes/no). Most of the participants (96\%) were able to identify the specific STI that they had. The most commonly reported STI were chlamydia and gonorrhea, reported by $63 \%$ of youth.

"Child maltreatment" included caretaker physical abuse, caretaker neglect and caretaker sexual abuse. "Caretaker physical abuse" was measured using an eight-item scale that asked youths questions such as how often a parent or adult caretaker who was supposed to be taking care of them threw something at them in anger, beat them up with their fist and threatened or assaulted them with a weapon. ${ }^{20}$ A mean procedure was performed to create a composite measure. Scale scores were coded such that the higher the score, the more abuse experienced $(\alpha=0.82)$. "Caretaker neglect" was measured with a 25-item scale that included items such as how often a parent or adult caretaker who was supposed to be taking care of them punished them by making them go a full day without food or water, abandoned them for at least 24 $\mathrm{h}$, said hurtful things or criticized them. A mean procedure was performed to create a composite measure. Scale scores were coded such that higher scores indicated higher levels of neglect $(\alpha=0.93)$. "Caretaker sexual abuse" was measured by a two-item scale that asked youths how often a parent or adult caretaker who was supposed to be taking care of them ever asked them to do something sexual or forced them to do something sexual. Owing to skewness, this composite measure was dichotomized $(0=$ no sexual abuse; $1=$ sexually abused at least once; $r=0.86)$.

For "street exposure," "age on own" was a single item that asked youths how old they were when they left home and were on their own for the first time. "Number of times run" was measured by one item in which respondents were asked how many times they had left home.

"Sexual histories" included age at first sex, number of sexual partners in the past 12 months and frequency of condom use. "Age at first sex" was a single item in which youths were asked how old they were the first time they had sex (the question did not specify whether it was oral, vaginal, or anal sex). "Number of sexual partners" was measured by asking youths how many different people they had sex with in the past 12 months. "Condom use" consisted of three items in which respondents were asked if they had used condoms in the past 12 months when they had vaginal sex, anal sex, and/or oral sex. A composite scale was created where the response categories were $0=$ no sex, $1=$ always used a condom, 2 = often used a condom, 3 = about half of the time used a condom, $4=$ seldom used a condom, and $5=$ never used a condom. A mean procedure was performed to create this composite measure where a higher score indicated less condom use during sex.

Trading sex and sexual victimization were indicators of "street experience." "Trading sex" was measured using four items in which respondents were asked if they had ever traded sex for food, shelter, money, or drugs since being on their own. The items were summed and then dichotomized because of skewness into $0=$ never traded sex for any of these items and $1=$ traded sex for at least one of these items $(\alpha=0.72)$. "Sexual victimization" consisted of two items that focused on whether young people had had any unwanted or unpleasant sexual experiences with people since they had been on their own. Youth were asked "how often have you been asked to do something sexual that you didn't want to" and "how often have you been sexually assaulted or raped?" This measure was dichotomized into $0=$ not sexually victimized, and $1=$ sexually victimized at least once $(r=0.51)$.

"Substance use" included frequency of alcohol use, ever having injected drugs, and frequency of illicit drug use. "Alcohol" was measured using two items in which respondents were asked about frequency of use of beer and hard liquor during the past 12 months. The response categories ranged from 0 (never) to 6 (daily). The two items were summed so that the higher the score, the more frequent the use of alcohol $(r=0.69)$. "Intravenous (IV) drug use" was measured by a single item in which youth were asked if they had ever injected themselves with drugs. Finally, "illicit drug use" was measured using seven items in which youth were asked if they had used crank, amphetamines, cocaine, opiates, hallucinogens, barbiturates, and inhalants in the past 12 months. The response category for each of these items was $0=$ never, $1=\mathrm{a}$ few times, 2 = monthly, 3 = weekly, and $4=$ daily. The value of hard-drug use was computed by using the highest value of these seven individual drugs. For example, if the youth reported daily use for inhalants but less than daily use for other drugs, the value of hard drug use was coded as 4 (daily use). Compared with the frequently used methods, such as average or sum procedure in much of the research, the approach used in the present study may give us more accurate information on youths' drug use involvement and addiction levels.

The study controlled for "age of youth" at time of interview. "Sex" was coded 0 for females and 1 for males. "Race" was contrast coded such that black $=1$; non-black $=0$; other 
races (including Hispanic, American Indian, Asian, bi-racial) were coded 1 ; non-other $=0$. Whites are the omitted category in the analyses. "Sexual orientation" was coded $1=$ heterosexual, and 0 = gay, lesbian or bisexual (GLB).

\section{Data analyses}

Bivariate associations between ever having an STI and dichotomous correlates were assessed by contingency table analysis. Prevalence ratios, their 95\% confidence intervals and their respective $P$-values were calculated. Student's $t$ tests were used to assess bivariate associations between ever having an STI and continuous correlates. The logistic regression model was used to calculate adjusted odds ratios (AOR), their 95\% confidence intervals and corresponding $P$-values. Significance was defined with an $\alpha$ of less than 0.05 .

\section{Results}

\section{Characteristics of the sample}

After list-wise deletion, the sample size for the current analyses was 370 . Females accounted for $58 \%$ of the sample (n $=213)$ and males accounted for $42 \%(n=157)$. Ages ranged from 16 to 19 years; the average age was 17.4 years. The majority (58\%) self-identified as European American, 22\% as African American, and 20\% as Hispanic, American Indian, Asian, or bi-racial. Approximately 15\% self-identified as gay, lesbian, or bisexual. Twenty-one per cent of young people said they have had an STI. Ninety-five per cent of youth had been physically abused, $100 \%$ of youth had experienced neglect, and $27 \%$ had been sexually abused. The mean for condom use was $\sim 2$, indicating that on average, youth reported using condoms often during sex. The average age of sexual onset was $\sim 14$ years, and youth reported an average of two partners in the past 12 months. The average age at which youth ran from home was 13 years, and youth ran an average of eight times. Thirty-nine per cent of youth reported being sexually victimized when on the streets, and 13\% had traded sex. Thirty-eight per cent reported using at least one illicit drug a few times or more, $82 \%$ reported alcohol use, and $\sim 10 \%$ reported they had injected drugs.

\section{Bivariate associations}

Table 1 displays bivariate associations between the dichotomous correlates and ever having had an STI. As shown, females were about three times more likely to have had an STI compared with males. Non-blacks were 38\% less likely to have an STI compared with blacks. Those who did not experience sexual abuse were $41 \%$ less likely to have had an STI compared with those who were sexually abused. Finally, youth who did not trade sex were $57 \%$ less likely to have had an STI compared with youth who did trade sex.

Table 2 displays bivariate associations between continuous correlates and ever having had an STI. As shown, those who had a greater number of sexual partners in the past 12 months and those who had lower rates of condom usage were significantly more likely to have had an STI.

\section{Multivariate associations}

Table 3 displays the significant multivariate associations. Males were $86 \%$ less likely to have had an STI compared
Table 1. Bivariate associations between dichotomous correlates and ever having a sexually transmissible infection (STI) $(n=370)$.

\begin{tabular}{|c|c|c|c|c|c|}
\hline Correlate & $n$ & $\%$ with STI & PR & $95 \% \mathrm{CI}$ & $P$ \\
\hline \multicolumn{6}{|l|}{ Sex } \\
\hline Female & 213 & 29.6 & 2.90 & $1.75-4.83$ & 0.000 \\
\hline Male & 157 & 10.2 & & & \\
\hline \multicolumn{6}{|l|}{ Sexuality } \\
\hline GLB & 54 & 24.1 & 1.15 & $0.69-1.94$ & 0.597 \\
\hline Heterosexual & 316 & 20.9 & & & \\
\hline \multicolumn{6}{|l|}{ Race $^{\mathrm{A}}$} \\
\hline Non-black & 288 & 18.8 & 0.62 & $0.41-0.92$ & 0.022 \\
\hline Black & 82 & 30.5 & & & \\
\hline Non-other & 295 & 20.3 & 0.80 & $0.51-1.26$ & 0.346 \\
\hline Other & 75 & 25.3 & & & \\
\hline \multicolumn{6}{|l|}{ Sexually abused } \\
\hline Not sexually abused & 272 & 18.0 & 0.59 & $0.40-0.87$ & 0.009 \\
\hline Sexually abused & 98 & 30.6 & & & \\
\hline \multicolumn{6}{|l|}{ Traded sex } \\
\hline Not traded sex & 323 & 18.3 & 0.43 & $0.29-0.64$ & 0.000 \\
\hline Traded sex & 47 & 42.6 & & & \\
\hline \multicolumn{6}{|l|}{ Sexually victimized } \\
\hline Not sexually victimized & 227 & 18.5 & 0.72 & $0.49-1.06$ & 0.092 \\
\hline Sexually victimized & 143 & 25.9 & & & \\
\hline \multicolumn{6}{|c|}{ Intravenous (IV) drug user } \\
\hline Not IV drug user & 335 & 21.5 & 1.08 & $0.54-2.15$ & 0.838 \\
\hline IV drug user & 35 & 20.0 & & & \\
\hline
\end{tabular}

A Whites are the omitted category.

$\mathrm{PR}$, prevalence ratio; CI, confidence interval; GLB, gay, lesbian, bisexual

Table 2. Bivariate associations between continuous correlates and ever having a sexually transmissible infection (STI) $(n=370)$

\begin{tabular}{lrrrc}
\hline \multirow{4}{*}{ Correlate } & No STI & Yes STI & $t$ & $P$ \\
\hline Age & 17.41 & 17.51 & -0.73 & 0.463 \\
Physical abuse & 1.35 & 1.34 & 0.19 & 0.853 \\
Neglect & 1.35 & 1.44 & -0.92 & 0.357 \\
Age on own & 13.30 & 13.39 & -0.26 & 0.798 \\
Number of times ran away & 7.93 & 10.23 & -1.61 & 0.108 \\
Age of sexual onset & 13.97 & 13.51 & 1.65 & 0.100 \\
Sexual partners in past 12 months & 2.25 & 2.89 & -2.55 & 0.011 \\
Condom use & 1.67 & 2.20 & -3.21 & 0.001 \\
Alcohol use & 2.84 & 2.90 & -0.22 & 0.826 \\
Illicit drug use & 1.66 & 1.63 & 0.17 & 0.864 \\
\hline
\end{tabular}

with females $(\mathrm{AOR}=0.14 ; 95 \% \mathrm{CI}=0.06-0.31)$. Blacks were almost four times more likely $(\mathrm{AOR}=3.71 ; 95 \% \mathrm{CI}=1.80$ 7.63) and other races were over two times more likely (AOR $=2.25 ; 95 \% \mathrm{CI}=1.08-4.67)$ to have had an STI compared with whites. For every one unit increase in the number of times youth ran away there was a 3\% increase in the likelihood of ever having had an STI (AOR $=1.03$; 95\% CI $=1.01$ 1.06). For every one unit increase in frequency of condom use there was a $61 \%$ decrease in the likelihood of an STI (AOR = $1.39 ; 95 \% \mathrm{CI}=1.10-1.76$ ). Finally, youth who traded sex were approximately two and a half times more likely to have had an STI compared with youth who did not trade sex $(\mathrm{AOR}=$ $2.36 ; 95 \% \mathrm{CI}=1.04-5.34)$. None of the remaining correlates approached multivariate significance. 
Table 3. Adjusted odds ratios for correlates of ever having a sexually transmissible infection (STI) $(n=370)$.

\begin{tabular}{lccc}
\hline Correlate & AOR & $95 \%$ CI & $P$ \\
\hline Age & 1.14 & $0.84-1.53$ & 0.404 \\
Sex $(0=$ female $)$ & 0.14 & $0.06-0.31$ & 0.000 \\
Sexuality $(0=$ GLB) & 1.26 & $0.57-2.78$ & 0.564 \\
Black $\left(0=\right.$ non-black) ${ }^{\mathrm{A}}$ & 3.71 & $1.80-7.63$ & 0.000 \\
Other races $(0=$ non-other $)$ & 2.25 & $1.08-4.67$ & 0.030 \\
Physical abuse & 0.71 & $0.42-1.21$ & 0.208 \\
Neglect & 1.05 & $0.64-1.73$ & 0.846 \\
Sexual abuse $(0=$ none) & 1.41 & $0.70-2.83$ & 0.340 \\
Age on own & 1.08 & $0.96-1.21$ & 0.212 \\
Number of times ran away & 1.03 & $1.01-1.06$ & 0.014 \\
Age of sexual onset & 0.90 & $0.79-1.02$ & 0.108 \\
Sexual partners in past 12 months & 1.13 & $0.97-1.32$ & 0.121 \\
Condom use & 1.39 & $1.10-1.76$ & 0.006 \\
Traded sex $(0=$ no) & 2.36 & $1.04-5.34$ & 0.040 \\
Sexual victimization $(0=$ none) & 0.63 & $0.32-1.21$ & 0.163 \\
Alcohol use & 1.02 & $0.88-1.18$ & 0.776 \\
Intravenous drug use $(0=$ no) & 1.14 & $0.39-3.31$ & 0.808 \\
Illicit drug use & 1.06 & $0.78-1.46$ & 0.701 \\
\hline
\end{tabular}

A Whites are the omitted category.

AOR, adjusted odds ratio; CI, confidence interval; GLB, gay, lesbian, bisexual.

\section{Moderating effects}

Although females were significantly more likely to have had an STI compared with males, a test for interactions revealed no significant sex differences. There were also no significant differences based on sexual orientation. However, two race interactions, both for blacks, were significant. Although alcohol use and condom use had little effect on white youth, lower levels of condom use and greater levels of alcohol use increased the probability of contracting an STI for black youth $(\mathrm{AOR}=2.09 ; 95 \% \mathrm{CI}=1.16-3.79 ; \mathrm{AOR}=1.46 ; 95 \% \mathrm{CI}$ =1.06-2.01 respectively).

\section{Discussion}

This study examined risk factors associated with ever having an STI among homeless youth in midwestern USA. Inconsistent condom use, spending more time on the street, and participation in trading sex were significantly associated with contracting an STI. These findings suggest that those homeless youth who spend more time on the street have more opportunities to be exposed to high-risk individuals and others who may exploit them and, hence, they are more likely to trade sex, which increases their risk for contracting STI. It is also possible that some of these youth have fewer resources than others (i.e. have no place to stay, are hungry) and may turn to trading sex to support themselves, which again increases their risk for STI. As expected, those who do not consistently wear condoms during sex are more likely to contract STI. Females are more likely to have STI compared with males, ${ }^{1,21}$ which may be explained by the fact that females often engage in sexual intercourse with older males, ${ }^{22}$ tend to have less control over the situation when it comes to condom use ${ }^{8}$ and experience higher rates of sexual victimization on the streets compared with males. ${ }^{23}$ Finally, black youth are more likely to have STI compared with white youth, ${ }^{1}$ which may be explained by the fact that blacks tend to initiate sexual intercourse at younger ages compared with whites ${ }^{24-26}$ and thus have a longer period of exposure, which increases their risk.

We know surprisingly little about the health effects of running away and homelessness among children and adolescents. Because these young people often leave highly abusive and neglecting families, it is safe to assume that many of their early health needs have been unmet. These problems are likely exacerbated by their participation in survival strategies (e.g. trading sex) and sexual risk-taking behaviors. Adolescence is a time of risk taking, perceived invulnerability, and experimentation with adult activities such as alcohol, drug use, and sexual activity. In normal development, this experimentation takes place in the context of adult monitoring, limitations, rules, and consequences that may moderate and constrain the degree of experimentation. Among runaway and homeless youth, however, these moderating factors do not exist ${ }^{16}$ and poor sexual health is a probable consequence.

Given the numerous reasons associated with poor sexual health among homeless youth (e.g. histories of abuse, sexual risk-taking behavior), a holistic approach to intervention may be necessary to improve their well being. This may be done through several means: increase awareness of STI through education programs in shelters, hand out free condoms and information pamphlets, provide youth with access to counselors in a non-judgmental setting, improve youths' self-efficacy, teach them sexual negotiation skills, and increase access and referrals to street clinics. Another targeted area should include sexual partners and members of social networks. Youth who are part of groups educated about safe sexual practices may be less likely to be coerced by other members into using drugs, trading sex, or engaging in unsafe sex. These interventions can be achieved through increasing access and referrals to clinics through street outreach programs/workers, by providing psychological counseling to youth, and by making homeless youth feel welcome in shelters. All of this will increase the chances of improving the sexual health of one of the most at-risk populations in our society.

\section{Limitations}

Findings are limited by the validity of the use of a convenience sample, self-reported measures, and the reliance on cross sectional data. Additionally, our measure of age at first sex did not take into account the specific type of sex that the respondent had (i.e., anal, vaginal, or oral). We also acknowledge that using a single-item, self-reported measure of STI is problematic because reliability and validity cannot be assessed. The prevalence of STI is likely to vary according to the source of data. ${ }^{27}$ Clark et al. ${ }^{28}$ found that only $46 \%$ of adolescents, albeit not homeless, accurately reported STI. Such inaccuracies are attributed to difficulties with recall and social desirability biases ${ }^{29,30}$ as well as the lack of routine testing with this population; ${ }^{6}$ therefore, the percentage given in the current study is likely an underestimate of the number of youth who have had an STI. For practical and ethnical reasons, selfreports may be the only feasible means of obtaining certain information, ${ }^{31}$ especially from homeless persons. The rate of STI found in the present study, however, is similar to other studies on homeless youth that use verified reports. ${ }^{32}$ 


\section{Conclusions}

Findings from the present study suggest that the amount of time youths spend on the street, their sexual practices, and their subsistence strategies are risk factors for contracting STI. Females and minority homeless youth are particularly at high risk. Intervention efforts that target the individual, their sexual partners, and peer groups in non-judgmental settings and efforts that increase access and referrals are most beneficial for lowering the risk for STI among this high-risk population.

\section{Acknowledgments}

This research was funded by the National Institute of Mental Health (MH 57110).

\section{References}

1 Centers for Disease Control and Prevention. Sexually transmitted disease surveillance, 2004. Atlanta, GA: US Department of Health and Human Services; 2005.

2 Weinstock H, Berman S, Cates W Jr. Sexually transmitted diseases among American youth: incidence and prevalence estimates, 2000. Perspect Sex Reprod Health 2004; 36: 6-10. doi: $10.1363 / 3600604$

3 Greene JM, Ennett ST, Ringwalt CL. Prevalence and correlates of survival sex among runaway and homeless youth. Am J Public Health 1999; 89: 1406-9.

4 Rew L, Chambers KB, Kulkarni S. Planning a sexual health promotion intervention with homeless adolescents. Nurs Res 2002; 51: 168-74. doi: 10.1097/00006199-200205000-00005

5 Tyler KA, Hoyt DR, Whitbeck LB. The effects of early sexual abuse on later sexual victimization among female homeless and runaway youth. J Interpers Violence 2000; 15: 235-50.

6 Johnson TP, Aschkenasy JR, Herbers MR, Gillenwater SA. Selfreported risk factors for AIDS among homeless youth. AIDS Educ Prev 1996; 8: 308-22.

7 Tyler KA, Whitbeck LB, Hoyt DR, Cauce AM. Risk factors for sexual victimization among male and female homeless and runaway youth. J Interpers Violence 2004; 19: 503-20. doi: 10.1177/0886260504262961

8 Bailey SL, Camlin CS, Ennett ST. Substance use and risky sexual behavior among homeless and runaway youth. J Adolesc Health 1998; 23: 378-88. doi: 10.1016/S1054-139X(98)00033-0

9 Halcon'LL, Lifson AR. Prevalence and predictors of sexual risks among homeless youth. J Youth Adolesc 2004; 33: 71-80. doi: 10.1023/A:1027338514930

10 MacKellar DA, Valleroy LA, Hoffmann JP, Glebatis D, LaLota $\mathrm{M}, \mathrm{McF}$ arland $\mathrm{W}$, et al. Gender differences in sexual behaviors and factors associated with nonuse of condoms among homeless and runaway youths. AIDS Educ Prev 2000; 12: 477-91.

11 Rew L, Fouladi RT, Yockey RD. Sexual health practices of homeless youth. J Nurs Scholarsh 2002; 34: 139-45. doi: 10.1111/ j.15475069.2002.00139.x

12 Wagner LS, Carlin L, Cauce AM, Tenner A. A snapshot of homeless youth in Seattle: their characteristics, behaviors and beliefs about HIV protective strategies. J Community Health 2001; 26: 219-32. doi: 10.1023/A:1010325329898

13 Forst ML. Sexual risk profiles of delinquent and homeless youths. J Community Health 1994; 19: 101-14. doi: $10.1007 / \mathrm{BF} 02260362$

14 Goodman E, Berecochea JE. Predictors of HIV testing among runaway and homeless adolescents. J Adolesc Health 1994; 15: 566-72. doi: 10.1016/1054-139X(94)90140-X

15 National Runaway Switchboard. Welcome to the national runaway switchboard. 2004. Online at: http://www.nrscrisisline. org/ [accessed 14 July 2006].

16 Tyler KA, Whitbeck LB. Lost childhoods: risk and resiliency among runaway and homeless adolescents. In: Allen-Meares $\mathrm{P}$, Fraser MW, editors. Intervention with children and adolescents: an interdisciplinary perspective. Boston, MA: Pearson Education; 2004. pp. 378-97.

17 Solorio MR, Milburn NG, Rotheram-Borus MJ, Higgins C, Gelberg L. Predictors of sexually transmitted infection testing among sexually active homeless youth. AIDS Behav 2006; 10: 179-84. doi: 10.1007/s10461-005-9044-8

18 Rohde P, Noell J, Ochs L, Seeley JR. Depression, suicidal ideation and STD-related risk in homeless older adolescents. J Adolesc 2001; 24: 447-60. doi: 10.1006/jado.2001.0382

19 Noell J, Rohde P, Seeley J, Ochs L. Childhood sexual abuse, adolescent sexual coercion and sexually transmitted infection acquisition among homeless female adolescents. Child Abuse Negl 2001; 25: 137-48. doi: 10.1016/S0145-2134(00)00223-4

20 Straus M, Gelles R. Physical violence in American families. Brunswick, NJ: Transaction Books; 1990.

21 Tyler KA, Whitbeck LB, Hoyt DR, Yoder KA. Predictors of selfreported sexually transmitted diseases among homeless and runaway adolescents. J Sex Res 2000; 37: 369-77.

22 Athey JL. HIV infection and homeless adolescents. Child Welf League Am 1991; 70: 517-28.

23 Tyler KA, Hoyt DR, Whitbeck LB, Cauce AM. The effects of a high-risk environment on the sexual victimization of homeless and runaway youth. Violence Vict 2001; 16: 441-55.

24 Upchurch DM, Levy-Storms L, Sucoff CA, Aneshensel CS. Gender and ethnic differences in the timing of first sexual intercourse. Fam Plann Perspect 1998; 30: 121-7. doi: $10.2307 / 2991625$

25 Miller BC, Norton MC, Curtis T, Hill EJ, Schvaneveldt P, Young $\mathrm{MH}$. The timing of sexual intercourse among adolescents: family, peer, and other antecedents. Youth Soc 1997; 29: 54-83.

26 Warren CW, Santelli JS, Everett SA, Kann L, Collins JL, Cassell C, et al. Sexual behavior among U.S. high school students, 1990-1995. Fam Plann Perspect 1998; 30: 170-2. doi: $10.2307 / 2991678$

27 Cates W. Teenagers and sexual risk taking: the best of times and the worst of times. J Adolesc Health 1991; 12: 84-94. doi: 10.1016/01970070(91)90449-V

28 Clark LR, Brasseux C, Richmond D, Getson P, D'Angelo LJ. Are adolescents accurate in self-reports of frequencies of sexually transmitted diseases and pregnancies? J Adolesc Health 1997; 21: 91-6. doi: 10.1016/S1054-139X(97)00042-6

29 Hingson R, Strunin L. Commentary: validity, reliability, and generalizability in studies of AIDS knowledge, attitudes, and behavioral risks based on subject self-report. Am J Prev Med 1993; 9: 62-4.

30 Kauth MR, St. Lawrence JS, Kelly JA. Reliability of retrospective assessments of sexual HIV risk behavior: a comparison of biweekly, three-month, and twelve-month self-reports. AIDS Educ Prev 1991; 3: 207-14.

31 Fitzgerald JL, Mulford HA. Self-report validity issues. J Stud Alcohol 1987; 48: 207-10.

32 Clatts MC, Rees Davis W, Sotheran JL, Atillasoy A. Correlates and distribution of HIV risk behaviors among homeless youths in New York City: implications for prevention and policy. Child Welf League Am 1998; 77: 195-207. 